\title{
A molecular method for biomonitoring of an exotic plant-pest: Leafmining for environmental DNA
}

\author{
Elia Pirtle ${ }^{1}$, Anthony Van Rooyen ${ }^{2}$, James Maino ${ }^{1}$, Andrew Weeks ${ }^{1}$, and Paul Umina ${ }^{1}$ \\ ${ }^{1}$ cesar Pty Ltd \\ ${ }^{2}$ cesar
}

November 2, 2020

\begin{abstract}
1. Understanding how invasive species respond to novel environments is limited by a lack of sensitivity and throughput in conventional biomonitoring methods. Arthropods in particular are often difficult to monitor due to small size, rapid lifecycles, and/or visual similarities with co-occurring species. This is true for the agromyzid leafminer, Liriomyza sativae, a global pest of vegetable and nursery industries that has recently established in Australia. 2. A highly robust method based on environmental DNA (eDNA) was developed exploiting traces of DNA left inside 'empty' leaf mines, which are easier to collect and persist longer in the environment than the insect. This extended the window of possible diagnosis to at least 28 days since a leaf mine became empty. The test allowed for visually indistinguishable leafmining damage caused by L. sativae to be genetically differentiated from that of other flies. 3. Field application resulted in the identification of new local plant hosts for L. sativae, including widely distributed weeds and common garden crops, with important implications for the pest's ability to spread. Moreover, the test allowed for the confirmation of L. sativae on an island with a previously unconfirmed population. 4. The developed eDNA method is likely to become an important tool for L. sativae and other leafmining species of biosecurity significance, which, historically, have been difficult to detect, diagnose and monitor. More generally, eDNA is emerging as a highly sensitive and labour-efficient surveillance tool for difficult to survey species to improve outcomes for agricultural industries, global health, and the environment.
\end{abstract}

\section{Introduction}

Invasive species continue to cause biodiversity loss (Kearney et al. 2018), loss of ecosystem services (Fei et al. 2019) and reduced profitability within agriculture (Pimentel et al. 2001). While Australia's large land mass may be uniquely protected by its natural isolation, increasing movement of humans and associated traded goods pose an increasing threat to biosecurity (Hulme 2016). Exotic pests were conservatively estimated to cost $\mathrm{A} \$ 13.6$ billion in 2011/12 in Australia, including both economic losses and management costs (Hoffmann and Broadhurst 2016). Arthropod pests alone are estimated to cost Australia's agricultural industries A $\$ 8$ billion annually (Bureau of Rural Sciences 2007; Canyon et al. 2011).

During a biological invasion, the area occupied (and associated impacts) accelerate through time (Fleming et al. 2017). Early-implemented prevention measures such as quarantine and surveillance are frequently more cost-effective than containment and asset-based protection (Epanchin-Niell and Hastings 2010; Moore et al. 2010). Furthermore, the cost of eradication is greatest for late detections when the area invaded is wider, and the likelihood of eradication success is lower (Rejmánek and Pitcairn 2002; Timmins and Braithwaite 2003). Conversely, early detection of exotic species, while populations are small and isolated, improves the success and cost of management, but requires high sensitivity, coverage, and robustness of surveillance methods 
(Dodd et al. 2015). The biology and ecology of the target species imposes limits on the ease of detection and diagnosis. For example, highly polyphagous pests can impede both surveillance and diagnostics when hosts are unknown, cryptic exotic species are difficult to distinguish from pre-existing native species causing delays in controlling the incursion (Hauser 2011), and the phenology of a pest may create a narrow window of detection or diagnosis (International Plant Protection Convention 2014).

Molecular methods that sequence DNA extracted from species tissue samples have become vital to biosecurity efforts (Armstrong and Ball 2005; Floyd et al. 2010) as they can overcome many of the limitations surrounding traditional diagnosis. Although routinely part of surveillance activities, collection of tissue samples can nonetheless be problematic due to small species sizes, rapid lifecycles, and elusive behaviours (Rajan 2006; Augustin et al. 2012). When specimens are difficult to collect, an alternative approach is to sample for biological excreta, including scat, hair, or feeding residues (Höss et al. 1992; Waits and Paetkau 2005; Rodgers and Janečka 2013; Valentin et al. 2018). More recently, advances in molecular technology permit the identification of species using only trace amounts of DNA found in the environment (Valentin et al. 2018).

Environmental DNA (eDNA) sampling utilises a species' residual DNA remaining in the environment. Environmental DNA has already shown itself to be a powerful tool for wildlife managers working with cryptic or elusive species (Sigsgaard et al. 2015; Smart et al. 2015). It has been widely applied to aquatic and semiaquatic ecosystems (Ficetola et al. 2008; Thomsen et al. 2012; Piaggio et al. 2014; Goldberg et al. 2015) due to the relative ease of isolating eDNA from water samples (Rodgers and Mock 2015). Environmental DNA monitoring can be more sensitive than traditional monitoring methods (Jerde et al. 2011; Dejean et al. 2012) and is capable of detecting species at low densities (Pilliod et al. 2013; Smart et al. 2015; Dougherty et al. 2016). Applying eDNA sampling to terrestrial environments can be challenging, although novel applications that exploit the unique ecology or lifecycle of target species are accumulating, such as isolating eDNA from predator wounds (Williams et al. 2003), browsed twigs (Nichols et al. 2015), soil (Andersen et al. 2012), leeches (Schnell et al. 2012), carrion-flies (Calvignac-Spencer et al. 2013; Schubert et al. 2015), crop surfaces (Valentin et al. 2018), and even the surface of flowers (Thomsen and Sigsgaard 2019). Here we explore the possibility of applying an eDNA approach to the early detection and diagnosis of a globally significant agricultural pest, the polyphagous vegetable leafminer, Liriomyza sativae Blanchard, highlighting the use of eDNA methods in biosecurity surveillance activities.

The Agromyzidae are a well-studied group of small flies whose larvae feed internally on plants, often as leaf and stem miners. Nearly all agromyzid species are very host-specific, although some are highly polyphagous and have become globally significant agricultural pests (Spencer 1973, 1990). This includes L. sativae, L. bryoniae(Kaltenbach), L. huidobrensis (Blanchard), L. trifolii(Burgess) and Chromatomyia horticola (Goureau), all of which mine plant leaves as larvae. While ecologically distinct, agromyzids are morphologically similar and can often only be distinguished via genitalia of adult flies (International Plant Protection Convention 2016). Moreover, the damage created by agromyzids is functionally indistinguishable between species. Of the exotic polyphagous leafminer, only L. sativae has been recorded in Australia (International Plant Protection Convention 2017), and it remains under quarantine. The cryptic nature of Liriomyza pests, and wide host ranges have made them historically difficult to detect and contain, allowing them to spread unchecked after an incursion (Powell 1981). Live specimens necessary for morphological identification are difficult to obtain. Adult flies are less than $2 \mathrm{~mm}$ in length, relatively inconspicuous in the environment and are only active at certain times of the day (Zehnder and Trumble 1984). Leaf mines are created by larval feeding, but the larvae will generally exit a plant leaf after one week, and thus old leaf mines are frequently detected on plants without living populations present (Johnson et al. 1980). Leafmining damage remains until the plant leaf dies. Traces of DNA within the mines will accumulate during defecation, moulting and if larvae are parasitised by hymenopteran wasps, making agromyzid leafminers an ideal candidate to test an eDNA approach.

Here, with an aim to enhance the sensitivity and robustness of leafminer diagnosis and biosecurity objectives, we develop a novel eDNA-based diagnostic method for $L$. sativae based on residual DNA inside empty leaf mines. Specifically, we answer how the sensitivity of the diagnostic is affected by: (i) different field 
preservation methods; (ii) DNA degradation due to field exposure time; and (iii) different plant hosts. We then demonstrate the effectiveness of the eDNA diagnostic by detecting a new incursion of $L$. sativae on an island in the Torres Strait. We present our work as four discrete experiments, which are visualized in Supplementary Figure S1.

\section{Methods}

\section{Field sites}

Field work was conducted in the Torres Strait and the Northern Peninsula Area of Cape York Peninsula, Queensland (Australia) between 2017 and 2019. Trial work took place across three sites on Thursday Island, including the Frog Gully community garden (referred to as "FGG"), a roadside near Thursday Island Hospital ("TIH") and Green Hill ("GHF"), and one site on the Australian mainland in the town of Injinoo ("INJ") where L. sativae has never been recorded. Active populations of $L$. sativae were present at the FGG and TIH sites, while activity was uncommon at the GHF site. The INJ site falls outside the current known range of L. sativae on the mainland. In addition to the trial work, the methods were tested on samples that had been collected as part of regular surveillance activities throughout the Torres Strait, including on Zuna Island, Horn Island and other regions on Thursday Island.

\section{Leaf mine preservation}

After collection of plant material, leaf mines were photographed and preserved into either $100 \%$ ethanol or onto a Whatmanß FTA card, both confirmed as suitable preservation techniques via a pilot study (see Supplementary Figure S2). For mines stored into ethanol, extra leaf material was cut away from the mine, and the mines were placed into a $2 \mathrm{~mL}$ Axygenß $\mathrm{B}$ tube with enough ethanol to submerge the mine $(\sim 0.75$ $-1 \mathrm{~mL}$ ). Leaf mines were typically up to $2.5 \mathrm{~mm}$ wide, and between 20 to $100 \mathrm{~mm}$ in length. For mines preserved onto FTA cards, leaves were rubbed, mine side down for about 30 seconds, onto the surface of the card. FTA cards were stored at $4{ }^{\circ} \mathrm{C}$ and ethanol samples at $-20{ }^{\circ} \mathrm{C}$ until analysis.

\section{Experimental groups}

'Positive control' samples refer to mines that were preserved with the larvae still present within the leaf. 'Zero day' samples refer to mines that were collected before larvae had naturally emerged, but the larva was then carefully removed by excision, before the mine was preserved. 'Unmined' samples refer to leaves that, after having been isolated in a mesh bag while still on living plants for at least four days, showed no signs of mines, and were therefore taken as absent of larvae. However, while these leaves had no visible signs of mining, L. sativae may still have been present in the area and may have had opportunity to deposit DNA on the leaf in the form of saliva and/or eggs that failed to hatch.

\section{Experiment 1 - Testing of unmined leaves in the field}

Trials were undertaken in the Torres Strait and Cape York Peninsula of Australia to investigate the potential for false positives from unmined leaves by the L. sativae eDNA method using siratro weed (Macroptilium atropurpureum ), a favoured host of L. sativae in the Torres Strait (Blacket et al. 2015). In 2018, ten random leaves of M. atropurpureum that showed no visible signs of leaf mining were selected at FGG. Each leaf was individually enclosed in a small mesh bag for the duration of the trial. The mesh bags were designed to prevent adult flies accessing the leaf surface, and thus prevent egg lay. After 11 days, each leaf was removed from their respective bag, visibly inspected for the presence of leaf mining, and placed into sealed plastic bags. In 2019, additional field trials were undertaken. A similar approach to the one described above was used except 15 random $M$. atropurpureum leaves were selected, and the trial repeated at three locations. 
These were FGG, GHF and INJ. At FGG and GHF, leaves were collected four days after the mesh bags were first installed, and immediately placed into sealed plastic bags. At the INJ site, a revisit was not possible after four days. The likelihood of L. sativae presence at this site was extremely low, so the unmined leaves were immediately collected and placed into sealed plastic bags. Plant samples from the 2018 and 2019 trials were transported back to the laboratory and stored at $-20{ }^{\circ} \mathrm{C}$ prior to molecular testing.

\section{Experiment 2 - eDNA persistence trial}

To determine the appropriate timeframe to examine the persistence of leafminer eDNA in the field, a pilot trial was conducted on a related and widespread species, L. brassicae (Riley), from which it was found that eDNA remained in leaf mines for at least 28 days under laboratory conditions (see Supplementary Figure S3). A field trial was then conducted at FGG on Thursday Island between July - August 2018 involving $L$. sativae. Seventy-three active leaf mines were identified on $M$. atropurpureum. These mines were randomly allocated to experimental groups ranging from 0 to 28 days. Within $24 \mathrm{~h}$, as a result of the rapid lifecycle of $L$. sativae in this tropical location, some of the larvae in selected leaf mines had already exited the mine. For those that did not emerge within $24 \mathrm{~h}$, the larvae were carefully excised manually, using a thin pair of tweezers, ensuring that the emergence hole created was no larger than for natural emergences. In this way, all larvae emerged, either naturally or artificially, on the same day. A photograph was taken of each mine at this point, for later reference.

Each leaf was then enclosed in a small mesh bag to ensure no further egg lay, and thus no additional leaf mining. Between 9 and 14 leaves were collected on days $0,1,3,7,14$ and 28 , and these were placed into separate sealed plastic bags and stored at $-20{ }^{\circ} \mathrm{C}$ prior to molecular testing.

In the first four days of the trial, all leaves were monitored closely to ensure only one leaf mine developed per leaf. If additional mines were observed forming due to eggs already present in the leaf before the addition of the mesh bag hatching, we immediately excised these additional larvae to prevent further development of the unwanted mines and replaced the mesh bags. To ensure the correct mine was ultimately collected, the photograph taken on day 0 of the desired mine was referenced upon collection. Any leaves for which the original mine was intersected by the formation of a new mine were discarded from the experiment.

A temperature logger (iButton@ Maxim Integrated) was placed inside a mesh bag and positioned in the shade among $M$. atropurpureumleaves. The logger recorded temperature and humidity every 10 minutes for the duration of the trial.

\section{Experiment 3 - eDNA sensitivity under field conditions}

The field-based sensitivity of the L. sativae eDNA method was explored on Thursday Island. Field-based sensitivity here refers to the proportion of leaves, all of which are known to have at some point been exposed to L. sativae DNA as a result of leaf mining, but for which the age, concentration, and level of degradation of the DNA is unknown, which yield positive detections via the eDNA test. Thus, the goal of this experiment was not to determine the actual threshold concentration of DNA which could be detected by the eDNA test (this was determined in the laboratory, see below), but rather to determine a realistic field measure of sensitivity, as the parameters of DNA age, concentration and degradation will almost always be unknown from field collected leaf mine samples. In May 2019, 288 mined leaves of $M$. atropurpureum were randomly selected from FGG and TIH (144 leaves at each location). Ninety-two leaf mines from each site were excised and placed into $2 \mathrm{~mL}$ Axygen $\mathrm{R}$ tubes with $100 \%$ ethanol. The remaining 52 leaves from each site were preserved onto FTA cards, following the methods described above. Prior to preservation, each mine was scored by its appearance as either fresh, medium or old (since mine age was unknown) and checked under the microscope for any remains of a larva (see Table 1 for specific scoring criteria). The length of each leaf mine was also estimated, and categorised as short $(<20 \mathrm{~mm})$, medium $(20-50 \mathrm{~mm})$ or long $(>50 \mathrm{~mm})$.

Unmined leaf samples were the same as those used during the 2019 trials in Experiment 1. 


\section{Experiment 4 - Field applications to delimit geographic range and host range}

To explore the utility of the L. sativae eDNA method to host plants beyond $M$. atropurpureum, we applied the test to a range of host plants, selected from field collections between 2018-2019 in Torres Strait where $L$. sativae is known to be present. In July 2018, leaf mines that looked similar in appearance to L. sativae mining were collected from chilli (Capsicum sp.), passionfruit (Passiflora edulis) and basil (Ocimum basilicum ) from FGG. A single leaf mine found on snakeweed (Stachytarphetajamaicensis ) was collected from Horn Island. In May 2019, five mines each from snakebean (Vigna unguiculata ssp.sesquipedalis), tomato (Solanum lycopersicum ), wild passionfruit (Passiflora foetida), and yellow alder weed (Turnera ulmifolia) were

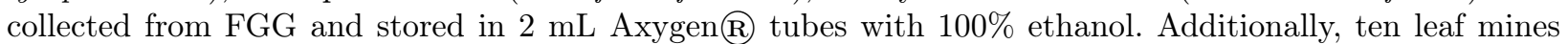
from $S$. jamaicensis (from a single patch of leaf mines discovered on Thursday Island), were collected and stored in $100 \%$ ethanol. These samples were transported back to the laboratory and stored at $-20{ }^{\circ} \mathrm{C}$ prior to molecular testing.

To further test the application of the eDNA methodology during delimiting survey activities, leaf mines were collected in July 2018 from seven leaf mines found in M. atropurpureum on Zuna Island, Queensland, a sparsely habited island where L. sativae had not been recorded previously and leaf mining activity was known to be very low. The leafmining damage discovered in $M$. atropurpureumappeared to be old, and none of the seven mines contained any active larvae that could be reared or preserved for identification. In June 2019, an empty leaf mine was also collected in Cairns, Queensland, from an eggplant (Solanum melongena ), a known host of L. sativae, but also a host of other leafminer species present in Australia.

In all instances, the empty leaf mines were closely inspected under the microscope prior to preservation, and some samples were found to contain visible remains of dead fly larvae. Sections of the mine that contained these remains were preserved, and analysed, separately from the rest of the empty mines to improve amplification of DNA.

\section{DNA extraction}

Total genomic DNA was extracted using a modified Chelex extraction protocol (Walsh et al. 1991). Individual leaf mines or $5 \mathrm{~mm}^{2}$ sections of FTA cards were placed into $1.5 \mathrm{ml}$ tubes along with a $3 \mathrm{~mm}$ glass bead (Retsch GmbH, Haan, Germany), $5 \mu \mathrm{L}$ of proteinase K and $200 \mu \mathrm{L}$ of $5 \%$ Chelex? solution. Each tube was then shaken in a Mixer Mill (MM300, Retsch GmbH, Haan, Germany) at 30 oscillations /s for 1 min. Samples were subsequently digested at $55{ }^{\circ} \mathrm{C}$ for $60 \mathrm{~min}$, followed by a final incubation at $95{ }^{\circ} \mathrm{C}$ for 15 min with periodic vortexing. Extractions were stored at $-20{ }^{\circ} \mathrm{C}$ until required. Prior to real time polymerase chain reaction (qPCR) amplification, extractions were spun at 10,000 g for $2 \mathrm{~min}$. Aliquots from the bottom half of the supernatant immediately above the Chelex resin was used for qPCR amplification.

\section{Molecular assays}

Species-specific PrimeTime qPCR assays (Integrated DNA Technologies) were used to target a 109 base pair (bp) fragment of the mitochondrial CO1 gene of L. sativae with sequences as described in Sooda et al. (2017) with the addition of two degenerate bases in the probe to accommodate sequence variants found within the Torres Strait Islands: NCBI accession KR476580 Haplotype S.28 (Blacket et al. 2015) and KR476573 Haplotype S.7 (Blacket et al. 2015). Forward primer SAT-F ACCCCCTGCTTTAACTCTTTT, reverse primer SATR AGCACCACCATGTGCAATAA and reporter probe SAT-P CAGTATAGTAGAAAATGGRGCTGGRA with a 6-FAM/ZEN/IBFQ modification.

We also developed a species specific PrimeTime qPCR assay to target a 63 bp fragment of the mitochondrial CO1 gene of L. brassicae for a pilot trial (see Supplementary Figure S2): NCBI accession KR476570 (Blacket et al. 2015). Forward primer GCCGGAACAGGATGAACAGTTTAT, reverse primer AGATGCCCCACCGTGAG, and reporter probe CCCCTCTCTTCTATTATTG with a 6-FAM/ZEN/IBFQ modification. Primer specificity was checked using a BLAST (Basic Local Alignment Search Tool) search against the 
National Institutes of Health NCBI (National Center for Biotechnology Information) nucleotide database (https://blast.ncbi.nlm.nih.gov/Blast.cgi), with no close matches found outside of L. brassicae.

The qPCR assays were tested for specificity against a panel of target and off-target Liriomyza genomic DNA diluted to 10 picograms. This included L. sativae, L. brassicae, L. trifoliiand L. huidobrensis, as well as DNA from four other species, L. yasumatsui, L. katoi, L. chenopodii and L. chinensis. Amplification was only evident in the respective target species, confirming species specificity of the assays developed for both L. sativae and L. brassicae .

PrimeTime qPCR assays were conducted using a Roche LightCycler 480 system (Roche Diagnostics Australia, Castle Hill, Australia) in a 384-well format. DNA extraction and $\mathrm{qPCR}$ assays were performed in separate isolated rooms. Reaction volumes were $10 \mu \mathrm{L}$, containing $5 \mu \mathrm{L}$ of KAPA probe force master mix (KAPA biosystems), $0.5 \mu \mathrm{L}$ PrimeTime qPCR assay (final primer and reporter probe concentration of 500 $\mathrm{nmol} / \mathrm{L}$ and $250 \mathrm{nmol} / \mathrm{L}$, respectively), $2.5 \mu \mathrm{L}$ ddH2O, and $2 \mu \mathrm{L}$ of DNA. Each reaction was prepared in triplicate. Included in each 384-well assay plate were control reactions containing genomic DNA of $L$. sativae that was serially diluted by a factor of $10(10 \mathrm{ng}$ to $0.01 \mathrm{pg})$ and a negative control with no DNA template. Quantitative PCR amplification conditions were $3 \mathrm{~min}$ at $98{ }^{\circ} \mathrm{C}$, followed by 50 cycles of 10 seconds at $95{ }^{\circ} \mathrm{C}$ and 20 seconds at $60{ }^{\circ} \mathrm{C}$. The absolute quantification module of the LightCycler 480 software package was used to calculate the assay efficiency and total amount of DNA in unknown samples based on the genomic DNA standard. The efficiency of all qPCRs was always $>90 \%$. All extractions and qPCR analyses were undertaken in a room that is dedicated to low-quantity DNA sources, with qPCR setup undertaken in a laminar flow-hood. Positive controls and standards were added immediately prior to placing samples in a Roche LightCycler 480. Negative controls were also included at all stages (DNA extraction, qPCR) so that laboratory contamination could be identified if present.

\section{Assay efficiency and sensitivity}

A tenfold dilution series ranging from 100 to 0.001 picogram of tissue derived gDNA, measured with a Qubit 2.0 fluorometer (Invitrogen, Carlsbad, CA, USA) was prepared in elution buffer AE (Qiagen). Ten replicates of each dilution were run and the reported $\mathrm{Cq}$ (cycle quantification) values were used to determine amplification efficiency, the coefficient of determination $\left(R^{2}\right)$ value as well as the limit of detection (LOD) and limit of quantification (LOQ) following the protocol and curve fitting method described in Klymuset al. (2019).

\section{Data analysis}

To estimate the required sampling protocol to achieve a predetermined level of diagnostic confidence under different conditions a hierarchical probabilistic model was used (Lugg et al. 2018). This model captured the nested effect of eDNA presence inside a leaf, and subsequent detectability through technical replicates of the molecular assay. Positive diagnosis of leafminer DNA was modelled as a nested Bernoulli variable: eDNA presence in the leaf mine $\left(Y_{i, j}=1\right)$ for each site $i$ and leafmine $j$ depends on the probability $\theta_{i, j}$ and; DNA presence in the extraction $\left(X_{i, j, k}\right)$ for each extraction $k$ depends on the parameter $p$ and whether there was extractable eDNA in the mine $\left(Y_{i, j}\right)$. Thus,

$$
\begin{aligned}
X_{i, j, k} & \sim \operatorname{Bern}\left(\mathrm{p} Y_{i, j}\right) \\
Y_{i, j} & \sim \operatorname{Bern}\left(\theta_{i, j}\right)
\end{aligned}
$$

The probability of viable eDNA in a leaf mine is assumed to covary with site and leaf conditions which are modelled through a logit link function:

$$
\operatorname{logit}\left(\theta_{i, j}\right)=a+B \mathbf{x}_{\mathbf{i}, \mathbf{j}}
$$


The model was fitted to observations using JAGS . Coefficients with $95 \%$ credible intervals were reported model parameters, including the binary covariates for preservation method (FTA versus ethanol), visible presence of larval remains (present versus absent), mine age (fresh versus not fresh), and mine length (long versus short/medium).

The probability of leafminer diagnosis $d$ can be estimated using the posterior distribution of model parameters as:

$$
d=1-\left(\left(1-\theta_{i, j}\right)\left(1-(1-p)^{N_{r}}\right)\right)^{N_{l}}
$$

where $N_{r}$ is the number of technical replicates and $N_{l}$ is the number of mined leaves tested.

\section{Results}

\section{Assay efficiency, sensitivity, and specificity}

Amplification efficiency was $99 \%$ and $96 \%$ with an $R^{2}$ value of 1.0 for the L. sativae and L. brassicae realtime qPCR assays, respectively. The LOD was $0.0056 \mathrm{pg}(0.0035 \mathrm{pg})$ of DNA and the LOQ was $0.022 \mathrm{pg}$ $(0.017 \mathrm{pg})$ of DNA for the L. sativae (L. brassicae) assay.

There was no off-target amplification of the seven Liriomyzaspecies for either assay, highlighting the specificity of these real-time qPCR assays.

\section{Experiment 1 - Testing of unmined leaves in the field}

During the 2018 trials, L. sativae was diagnosed in 1 out of 10 of the unmined leaves, with a low DNA concentration found ( $1 \mathrm{pg}$ DNA in 2 of 3 replicate qPCR tests). DNA concentrations from the "positive control' samples averaged $123 \mathrm{pg}$ across 71 samples tested (Figure 1).

During the 2019 trials, L. sativae was diagnosed in 2 out of 45 unmined leaves, with low DNA concentrations detected ( $<2$ pg DNA in all three replicate qPCR tests). The two leaves with a low (but positive) diagnosis were collected from areas with known L. sativae activity, FGG and GHF. However, DNA of L. sativae was not amplified in any of the INJ unmined leaves, where L. sativaehas never before been recorded.

\section{Experiment 2 - eDNA persistence trial}

Temperatures recorded over the period during which the leaf mines were ageing ranged from $20.1{ }^{\circ} \mathrm{C}$ to 37.6 ${ }^{\circ} \mathrm{C}$ (averaging $29.5^{\circ} \mathrm{C}$ in the daytime and $26.7^{\circ} \mathrm{C}$ overnight) and relative humidity levels ranged from $33.8 \%$ to $98.7 \%$ (averaging $64.3 \%$ in the daytime and $73.6 \%$ overnight). While the amount of DNA amplified varied widely with age of leaf mines (Figure 1), DNA was still diagnosable within leaf mines after 28 days, and the average success rate for diagnosis from an empty leaf mine (a successful diagnosis being the case where at least one of three replicate qPCR tests for an individual leaf mine yielded positive results) for mines between 0 and 28 days old was $65.1 \%$ (Figure 2). There was no effect of age of the leaf mine $(F=2.5, \mathrm{df}=1, p=$ 0.12 ) on the concentration of DNA amplified from the leaf material.

\section{Experiment 3 - eDNA sensitivity under field conditions}

Of the 184 leaf mine samples from M. atropurpureum directly preserved in ethanol, $82.1 \%$ yielded a positive diagnosis of $L$. sativae (on at least one of three replicate qPCR tests) and $17.9 \%$ yielded no diagnosis. Of 
the 104 leaf mines preserved onto FTA cards, $58.7 \%$ yielded a positive diagnosis of $L$. sativae (on at least one of three replicate qPCR tests) and $41.3 \%$ yielded no diagnosis.

There was no effect of leaf mine age $(\mathrm{F}=0.5, \mathrm{df}=2, p=0.60)$ or leaf mine length $(\mathrm{F}=2.5, \mathrm{df}=2, p=$ 0.09 ) on the concentration of DNA amplified from the leaf material. However, there was a significant effect of larval remains on the concentration of DNA amplified within a leaf mine $(F=3.5, \mathrm{df}=8, p<0.001)$. For mines preserved in ethanol, those containing the remains of a fly larva amplified on average $488.5(+116) \mathrm{pg}$ of DNA compared with $36.4(+22)$ pg from mines that did not contain larval remains. For mines preserved onto FTA cards, those containing larval remains amplified on average $10.5(+10)$ pg of DNA compared with $0.09(+0.03) \mathrm{pg}$ for those mines that did not contain larval remains. For leaf mines preserved in ethanol that did not contain larval remains, $89.4 \%$ yielded a positive diagnosis.

Using the multilevel detection probability model incorporating uncertainty at the eDNA and qPCR stages, it was estimated that the probability of $L$. sativae diagnosis increased with the number of mined leaves and technical replicates tested as shown by the positive coefficients in Table 2 (with the exception of FTA storage). If DNA was present in a leaf mine, each qPCR replicate had an estimated $80 \%$ chance of confirming presence (with three technical replicates providing over $99 \%$ chance of confirmation). Of the covariates tested, the presence of larval remains and the preservation method were found to have significant effects on the probability of L. sativae diagnosis (Table 2). The presence of larval remains increased the probability of diagnosis by 9 times, while the use of FTA cards for preservation decreased the probability by 5 times compared with preservation of empty leaf mines in ethanol (Table 2).

Assuming three technical qPCR replicates and samples are preserved in ethanol, testing of only two empty leaf mines is estimated to provide a $90 \%$ probability of $L$. sativae diagnosis, even if there are no larval remains present, the leaf itself is not fresh, and the mine is $50 \mathrm{~mm}$ (or less) in length (Figure 3). Three empty leaf mines provided a greater than $90 \%$ probability (as indicated by the $95 \%$ credible interval in Figure 3 )

\section{Experiment 4 - Field applications to delimit geographic range and host range}

The empty mine eDNA method was applied to several plant samples collected within, and outside of the known range of $L$. sativae in Australia. Of the mines collected from known host plants of $L$. sativae on Thursday Island, all collected mines from $S$. lycopersicum and a single mine from $V$. unguiculata were confirmed to be L. sativae (Table 3). Of the mines collected from plants which were not known to be a host L. sativae in the Torres Strait, namely Capsicum sp., P. edulis, T. ulmifolia, O. basilicum and $S$. jamaicensis, at least one mine per host plant was confirmed to be L. sativae. This constitutes the first formal record of mining activity of L. sativae in these plants in Australia.

Of the mines collected outside the known range of $L$. sativae, five (of the seven) leaf mines from $M$. atropurpureum collected on Zuna Island were confirmed as L. sativae, while the leaf mine collected from $S$. melongena in Cairns was not found to beL. sativae (Table 3)

\section{Discussion}

The eDNA method developed here was shown to be highly robust under field conditions, reliably detecting and diagnosing $L$. sativae DNA from empty leaf mines under tropical conditions. This novel approach significantly increases the surveillance opportunity for this invasive pest and is likely to be highly transferable to other globally important agromyzid flies. Preservation methods of collected leaf samples were found to be important with $100 \%$ ethanol being the most reliable collection procedure (but FTA cards were also feasible). There was no decline in diagnostic success measured up to 28 days after the emergence of larvae from a mine. Other forms of arthropod eDNA, such as that of the tiger mosquito (Aedes albopictus), have been shown to persist in the environment for similar lengths of time (Schneider et al. 2016). 
Preliminary field applications have already highlighted the utility of the eDNA method through identification of new local hosts, includingS. jamaicensis, C. annuum, T. ulmifolia, P. edulisand O. basilicum, and the first occurrence record of $L$. sativae on Zuna Island. These results widen the range of hosts that will be considered during routine surveillance aimed at containing this pest. While the current preference for these host plants appears low, the occurrence patterns of these plants could nevertheless make them important vectors of spread. Passiflora edulis , C. annuumand O. basilicum are common garden plants, with O. basilicum posing a particular risk given it is a popular herb that is routinely transported by tourists and locals as living plants.Stachytarpheta jamaicensis is a very common and widely distributed weed, particularly in disturbed areas throughout northern Queensland and other parts of Australia (Atlas of Living Australia 2019). This new knowledge has already been used by the Northern Australian Quarantine Strategy in their regular surveillance programs for L. sativae (B. Waterhouse and S. Cowan, pers. comm.).

Out of 45 unmined leaves, two 'false positives' occurred (with $<2$ pg DNA detected in all three replicate qPCR tests). It is unclear whether these were false positives in the true sense (as a result of off-target DNA being amplified by the eDNA assay), whether they were the result of laboratory contamination (despite careful sample hygiene where negative control leaves were collected and processed in a different laboratory than mined leaves and with heat sterilized equipment), or whether there was indeed L. sativae DNA already present on the unmined leaves. Both 'false positives' came from unmined leaves that were collected from sites with adult $L$. sativaeactivity present, FGG and GHF. The lack of any false positives from INJ, the only site included with no known presence of $L$. sativae, increases our confidence in the reliability of the eDNA assay. False positives can be a concern within a biosecurity surveillance program. For instance, a false positive could trigger unnecessary economic losses as a result of unwarranted trade restrictions, while a false negative could delay the detection of an incursion of a pest or disease, reducing the odds of eradication and increasing the costs of control (Fleming et al. 2017; Epanchin-Niell and Hastings 2010; Moore et al. 2010). Thus, the cost of errors must be weighed alongside the goals of the surveillance program and the resources available (Garrard et al. 2008). For early detection surveillance, a less conservative survey method or diagnostic test that aims to reduce the chances of false negatives may be preferred. Similarly, equivocal eDNA assay results (where one or two technical replicates out of three yield a positive detection) should be considered in a similar manner, particularly in areas where the target species has not been detected previously. Given biosecurity response decisions are typically based on a high level of confidence, equivocal results would serve as an indicator that further surveillance and diagnostic testing is warranted.

In this study, we developed and tested the in-field reliability and practicality of an eDNA assay for leaf mines (Experiments 1 through 3), and applied this to better understand the dynamics of the current incursion of $L$. sativae within Australia (Experiment 4). Leaf mined samples tended to be quite rare in our field surveys and thus represented a relatively small sample size, sometimes being comprised of only a single leaf mine (Table 3). This is to be expected in early incursions undergoing range and host expansions (Liebhold et al. 2020). Nonetheless, analysis of samples collected during our survey indicate expansions in the known geographic and host range of L. sativae. The eDNA assay therefore has the potential for detecting incursions at an early stage, which is more likely to increase the success of a biosecurity response (Fleming et al. 2017; EpanchinNiell and Hastings 2010; Moore et al. 2010). The identification of a new L. sativaehost plant within the Torres Strait, S. jamaicensis, is particularly noteworthy and has already directed surveillance programs being undertaken in Australia by government agencies.

The eDNA method developed herein is likely to become an important tool for distinguishing agromyzids that remain a biosecurity threat to Australia's agricultural industries. It presents a new opportunity to reduce the spread of exotic leafminers, which, historically, have been difficult to detect and contain overseas due to poor host records and overlap with native leafminers (Powell 1981). For example, not only is the leaf mining damage created by $L$. sativaeindistinguishable from other high-risk exotic agromyzids, including $L$. trifolii and L. huidobrensis, it can also be easily confused with the closely related $L$. brassicae, already common in Australia, which not only creates indistinguishable damage on many of the same plants as L. sativae, but is also indistinguishable as an adult by any means other than dissection or molecular analysis (Shiao 2004; International Plant Protection Convention 2016). 
The utility of eDNA in biosecurity programs will extend beyond leafmining species. For example, eDNA approaches using samples collected from water bodies have greater sensitivity compared with traditional surveillance techniques for invasive mosquito larvae (Aedes albopictus, A. japonicus japonicus and A. koreicus ) (Schneider et al. 2016) and the invasive American bullfrog (Rana catesbeiana) (Dejean et al. 2012). Yet, there remain many unexplored opportunities to apply eDNA to enhance detection of exotic species, particularly in the terrestrial realm. Recently, eDNA approaches have been developed to detect the highly invasive brown marmorated stinkbug (Halyomorpha halys) in orchards from water reservoirs used to wash fruit as well as bat faecal material; both methods achieved a higher sensitivity than traditional trapping methods such as light and pheromone traps (Maslo et al. 2017; Valentin et al. 2018). Opportunities for early detection of other exotic invertebrate pests also exist and remain to be explored. For instance, the giant African snail (Lissachatina fulica) leaves a trail of slime that is likely to include their DNA and developing an efficient eDNA sampling protocol could be a more sensitive method of detection at borders (e.g. sea ports). Beyond early detection of exotic species, scalable and high-throughput eDNA techniques should become increasingly valuable for routine monitoring programs. Such technologies will increase the efficiency and sensitivity of both delimiting responses and proof of area freedom assessments, where the large-scale sampling necessary for statistical reliability is often associated with large time and labour costs (Gambley et al. 2009; Abdalla et al. 2012).

Although promising, eDNA will not always result in reliable diagnostics. Derocles et al. (2015) used a mini-barcoding approach to target degraded DNA inside empty leaf mines in a number of plant hosts, but found only $6 \%$ of the mines collected from the field (and therefore of an unknown age) allowed for species identification, and only $33 \%$ of the mines with a known age (where the emergence of the leafminer was observed and recorded) allowed for identification. This is far lower than the detectability we found for $L$. sativae. In part, this may be attributed to the use of general primers (designed for a range of lepidopteran and dipteran species) and PCR conditions not optimised to highly degraded DNA (Derocles et al. 2015). Within our study, a highly specific qPCR assay for L. sativae was applied that could detect L. sativae DNA quantities as low as $0.1 \mathrm{pg}$. The use of specific primers, qPCR detection, as well as improved DNA extraction methods is likely to have accounted for the higher detection rates compared with previous studies.

In many cases, eDNA approaches may not replace traditional surveillance techniques, but rather complement them for improved detection (Schneider et al. 2016). In situations where false positives could lead to considerable economic losses (e.g. trade restrictions being imposed), morphological support should ideally complement molecular tests. Further, the success of an eDNA approach will be dependent on the target species lifecycle and biology. To determine the potential for a successful eDNA approach, one must consider what traces a target species might leave behind in its environment, and where those traces are most likely to be concentrated. For example, species with highly localised activity, such as pollinating insects (Thomsen and Sigsgaard 2019), may be more conducive to such an approach than transient species. However, it may be possible to improve detection rates for transient species via 'eDNA traps' that take advantage of the target species' behaviour or industry practices that concentrate eDNA. Burns et al. (2020) employed a novel eDNA trap to detect the threatened Baw Baw frog (Philoria frosti) and its' key threatening pathogen chytridiomycosis. The application of eDNA in terrestrial environments is challenging, but innovative approaches can result in achieving methods being developed that are more sensitive and efficient than traditional approaches.

As the interconnectedness of global economies continues to remove spatial barriers between regions, biosecurity technologies must keep pace to mitigate the enormous pressures from alien species placed on biological systems. Novel eDNA methods based on modern technologies can play an important role in modern biosecurity efforts to protect both natural and agricultural ecosystems.

\section{Tables and Figures}

Table 1. Classifications used to assess the age of leaf mines and presence of larva in L. sativae sensitivity trials. 


\begin{tabular}{llll}
\hline Characteristic & Classification & Description & Image \\
\hline Mine age & Fresh & mine is white and a black trail of frass is visible \\
& Medium & mine is mostly white, but with some browning and frass is less distinct \\
Old & mine is mostly brown and frass is mostly indistinct \\
Presence of larva & Larva removed & a healthy larva was present and excised from the mine \\
& Dead larva & the remains of a dead larva were present within the mine \\
& Empty & no remains of a larva were present within the mine & \\
\hline
\end{tabular}

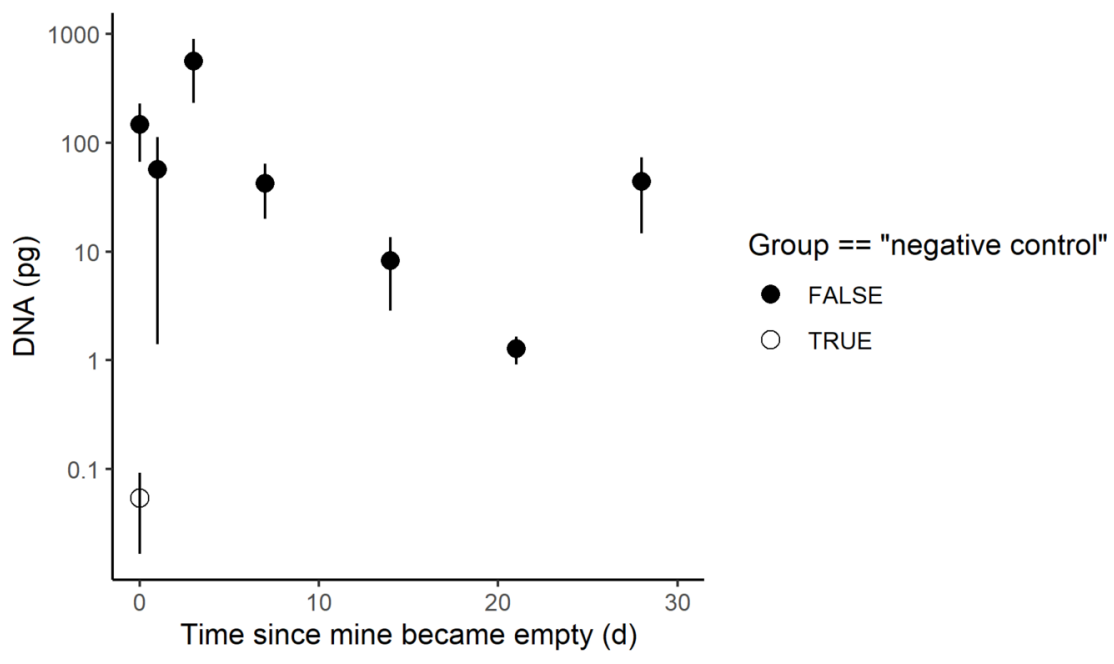

Figure 1. Average concentration of L. sativae DNA (picograms on a log transformed scale) amplified in M. atropurpureum leaf mines, 0 - 28 days after emergence of a larva . Vertical bars represent standard errors. The open circle at day 0 shows the unmined leaf samples from Experiment 1 (2018 and 2019 samples combined).

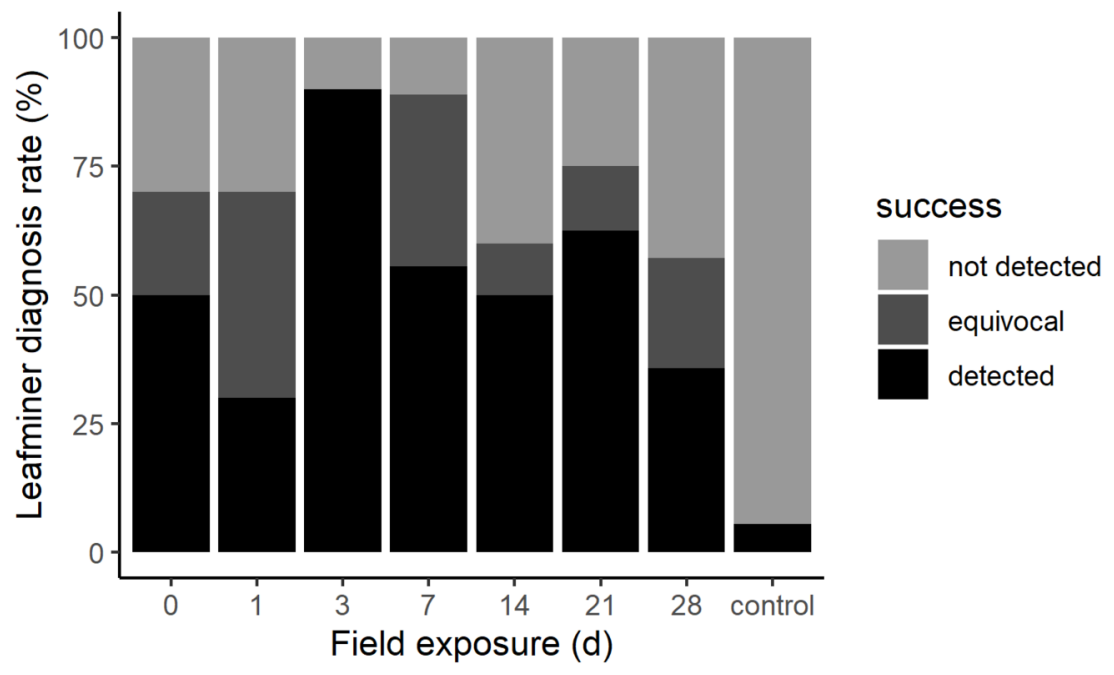

Figure 2. Percent of M. atropurpureum leaves in each age group that yielded a positive L. 
sativae detection ( 3 successful qPCR tests), that yielded equivocal results ( 1 or 2 of the 3 qPCR tests were successful) or that did not yield a detection (all 3 qPCR tests failed to detect). The column on the right shows the unmined leaf mine samples from Experiment 1 (2018 and 2019 samples combined).

Table 2. Estimated coefficients for fitted model of

L. sativae diagnosis probability with standard deviations (SD) and credible intervals (CI).

\begin{tabular}{llll}
\hline Coefficient & Mean & SD & CI $(95 \%)$ \\
\hline Probability of eDNA in leaf mine & Probability of eDNA in leaf mine & Probability of eDNA in leaf mine & Probability of e \\
$\vartheta$ (logit-linked linear covariates) & $\vartheta$ (logit-linked linear covariates) & $\vartheta$ (logit-linked linear covariates) & $\vartheta($ logit-linked l \\
a (intercept) & 0.7 & 0.1 & $(0.5,0.8)$ \\
Preservation method = FTA & -1.6 & 0.3 & $(-2.3,-1)$ \\
Larval remains = present & 2.2 & 0.5 & $(1.4,3.2)$ \\
Mine age = fresh & 0.4 & 0.4 & $(-0.3,1.2)$ \\
Mine length = long (> 50 mm) & 0.3 & 0.4 & $(-0.5,1)$ \\
Probability of qPCR detection & Probability of qPCR detection & Probability of qPCR detection & Probability of q \\
p & 0.8 & 0.0 & $(0.8,0.9)$ \\
\hline
\end{tabular}

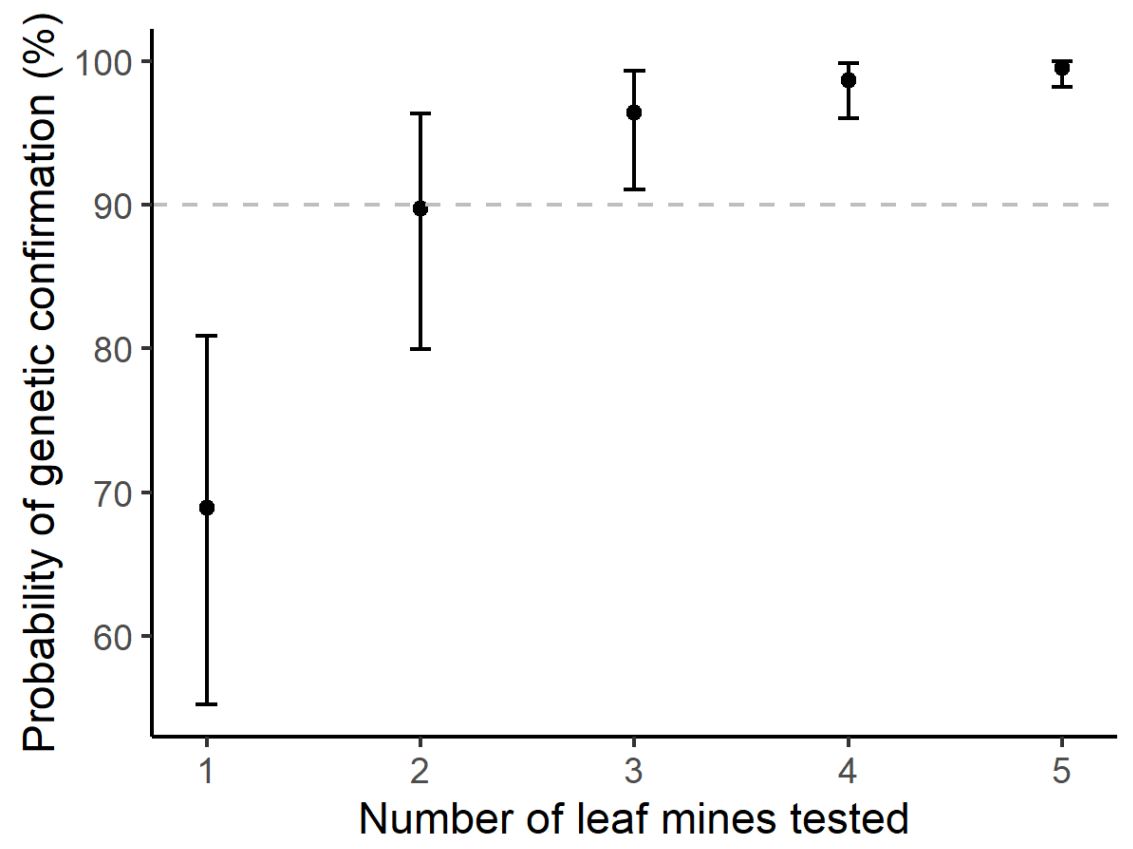

Figure 3. Estimated probability of L. sativae diagnosis with number of empty leaf mines in M. atropurpureum. Vertical bars represent standard errors. Estimates assume three technical qPCR replicates, storage of leaf mines in ethanol, leaf mines contain no larval remains, and leaf mines are not fresh and $<50 \mathrm{~mm}$ in length.

Table 3. Results of L. sativae empty mine eDNA analysis for noteworthy samples from surveillance activities undertaken between 2018 and 2019. Samples that represent a previously unconfirmed location for $L$. sativae are indicated in bold. 


\begin{tabular}{lllll}
\hline Host plant & Location & Year & Sample type* & No. specimens pooled per sample** \\
\hline Capsicum sp. & Thursday Island & 2018 & empty mine & 1 \\
O. basilicum & Thursday Island & 2018 & larval remains & 1 \\
O. basilicum & Thursday Island & 2018 & empty mine & 1 to 5 \\
M. atropurpureum & Zuna Island & $\mathbf{2 0 1 8}$ & larval remains & $\mathbf{1}$ \\
M. atropurpureum & Zuna Island & $\mathbf{2 0 1 8}$ & empty mine & $\mathbf{1}$ \\
P. edulis & Thursday Island & 2018 & larval remains & 2 \\
P. edulis & Thursday Island & 2019 & empty mine & 1 \\
P. edulis & Thursday Island & 2019 & larval remains & 3 \\
P. foetida & Thursday Island & 2019 & unknown & 1 \\
T. ulmifolia & Thursday Island & 2019 & larval remains & 5 \\
T. ulmifolia & Thursday Island & 2019 & unknown & 1 \\
S. lycopersicum & Thursday Island & 2019 & unknown & 1 \\
S. melongena & Cairns & 2019 & empty mine & 2 \\
S. jamaicensis & Thursday Island & 2019 & larval remains & 10 \\
S. jamaicensis & Thursday Island & 2019 & unknown & 1 \\
S. jamaicensis & Horn Island & 2019 & larval remains & 1 \\
V. unguiculata ssp. sesquipedalis & Thursday Island & 2019 & unknown & 1 \\
\hline
\end{tabular}

* larval remains $=$ remains of a dead fly larva was inside the leaf mine and that section of mine was preserved for analysis, empty mine $=$ no signs of larval remains inside the leaf mine, unknown $=$ leaf mine not examined under a microscope and thus unknown if it was empty or contained larval remains.

** In some cases, multiple specimens (either multiple leaf mines or multiple larval remains) were pooled into a single sample to ensure sufficient DNA to make an identification.

*** At least 1 out of 3 replicate qPCR tests was positive for $L$. sativae.

\section{Author Contribution Statement}

All authors conceived and designed the research. EP and PU conducted the experiments, AvR conducted the molecular analyses, and JM conducted the statistical analyses. EP led the development of the manuscript, with contributions from all authors.

\section{Acknowledgements}

The authors would like to thank the Cairns, Thursday Island and Seisia offices of the Northern Australia Quarantine Strategy (NAQS - Australian Government Department of Agriculture) for support throughout this project. In particular, the authors thank Dr. Barbara Waterhouse and Dr. Sally Cowan for logistical support, technical knowledge and provision of samples, as well as Harold Matthew and Ilana Foster for invaluable assistance in running the field experiments. The authors also acknowledge the Torres Strait Regional Authority, Torres Shire Council, Kaurareg Native Title Aboriginal Corporation, Northern Peninsula Area Regional Council, Seisia Enterprises, Apudthama Land Trust, and MyPathways who provided permission and support to conduct experiments within the Torres Strait and the Northern Peninsula Area. Thanks also to Dr. Mallik Malipatil and Dr. Peter Ridland for assistance with morphological identifications and provision of some leafminer samples, and Dr. Olivia Reynolds for technical support on the manuscript. Finally, we thank the two anonymous reviewers for their thoughtful comments. 


\section{Compliance with Ethical Standards}

Funding : This study was supported by funding from Hort Innovation via the vegetable and nursery research and development levies and contributions from the Australian Government.

Conflict of Interest : The authors declare that they have no conflict of interest.

\section{Data availability}

Sequencing data is freely available on NCBI: accessions KR476580, KR476573 and KR476570 (Blacket et al. 2015).

\section{References}

Abdalla A, Millist N, Buetre B, Bowen B (2012) Benefit-cost analysis of the National Fruit Fly Strategy Action Plan Report. 45

Andersen K, Bird KL, Rasmussen M, et al (2012) Meta-barcoding of "dirt" DNA from soil reflects vertebrate biodiversity. Mol Ecol 21:1966-1979. https://doi.org/10.1111/j.1365-294X.2011.05261.x

Armstrong KF, Ball SL (2005) DNA barcodes for biosecurity: Invasive species identification. Philos Trans R Soc B Biol Sci 360:1813-1823. https://doi.org/10.1098/rstb.2005.1713

Augustin S, Boonham N, De Kogel WJ, et al (2012) A review of pest surveillance techniques for detecting quarantine pests in Europe. EPPO Bull 42:515-551. https://doi.org/10.1111/epp.2600

Australia A of L Macroptilium atropurpureum (DC.) Urb. http://www.ala.org.au/. Accessed 29 Oct 2019

Blacket MJ, Rice AD, Semeraro L, Malipatil MB (2015) DNA-based identifications reveal multiple introductions of the vegetable leafminerLiriomyza sativae (Diptera: Agromyzidae) into the Torres Strait Islands and Papua New Guinea. Bull Entomol Res 61:1-12. https://doi.org/10.1017/S0007485315000383

Bureau of Rural Sciences (2007) Australia - Our Natural Resources at a Glance - 2007. Canberra

Burns T, Clemann N, van Rooyen A, et al (2020) Environmental DNA sampling in a terrestrial environment: methods to detect a critically endangered frog and a global pathogen. bioRxiv. https://doi.org/10.1101/2020.03.01.968693

Calvignac-Spencer S, Merkel K, Kutzner N, et al (2013) Carrion fly-derived DNA as a tool for comprehensive and cost-effective assessment of mammalian biodiversity. Mol Ecol 22:915-924. https://doi.org/10.1111/mec.12183

Canyon D, Naumann I, Speare R, Winkel K (2011) Environmental and economic costs of invertebrate invasions in Australia. Biol Invasions 25-50. https://doi.org/10.1201/b10938-5

Dejean T, Valentini A, Miquel C, et al (2012) Improved detection of an alien invasive species through environmental DNA barcoding: The example of the American bullfrog Lithobates catesbeianus . J Appl Ecol 49:953-959. https://doi.org/10.1111/j.1365-2664.2012.02171.x

Derocles SAP, Evans DM, Nichols PC, et al (2015) Determining plant-leaf miner-parasitoid interactions: a DNA barcoding approach. PLoS One 10:e0117872. https://doi.org/10.1371/journal.pone.0117872

Dodd AJ, Ainsworth N, Burgman MA, Mccarthy MA (2015) Plant extirpation at the site scale: Implications for eradication programmes. Divers Distrib 21:151-162. https://doi.org/10.1111/ddi.12262 
Dougherty MM, Larson ER, Renshaw MA, et al (2016) Environmental DNA (eDNA) detects the invasive rusty crayfish Orconectes rusticus at low abundances. J Appl Ecol 53:722-732. https://doi.org/10.1111/1365-2664.12621

Epanchin-Niell RS, Hastings A (2010) Controlling established invaders: Integrating economics and spread dynamics to determine optimal management. Ecol Lett 13:528-541. https://doi.org/10.1111/j.14610248.2010.01440.x

Fei S, Morin RS, Oswalt CM, Liebhold AM (2019) Biomass losses resulting from insect and disease invasions in US forests. Proc Natl Acad Sci 116:17371-17376. https://doi.org/10.1073/pnas.1820601116

Ficetola GF, Miaud C, Pompanon F, Taberlet P (2008) Species detection using environmental DNA from water samples. Biol Lett 4:423-425. https://doi.org/10.1098/rsbl.2008.0118

Fleming PJS, Ballard G, Reid NCH, Tracey JP (2017) Invasive species and their impacts on agri-ecosystems: Issues and solutions for restoring ecosystem processes. Rangel J 39:523-535. https://doi.org/10.1071/RJ17046

Floyd R, Lima J, de Waard J, et al (2010) Common goals: Policy implications of DNA barcoding as a protocol for identification of arthropod pests. Biol Invasions 12:2947-2954. https://doi.org/10.1007/s10530010-9709-8

Gambley CF, Miles AK, Ramsden M, et al (2009) The distribution and spread of citrus canker in Emerald, Australia. Australas. Plant Pathol. 38:547-557

Garrard GE, Bekessy SA, McCarthy MA, Wintle BA (2008) When have we looked hard enough? A novel method for setting minimum survey effort protocols for flora surveys. Austral Ecol 33:986-998. https://doi.org/10.1111/j.1442-9993.2008.01869.x

Goldberg CS, Strickler KM, Pilliod DS (2015) Moving environmental DNA methods from concept to practice for monitoring aquatic macroorganisms. Biol Conserv 183:1-3. https://doi.org/10.1016/j.biocon.2014.11.040

Hauser M (2011) A historic account of the invasion of Drosophila suzukii (Matsumura) (Diptera: Drosophilidae) in the continental United States, with remarks on their identification. Pest Manag Sci 67:1352-1357. https://doi.org/10.1002/ps.2265

Hoffmann BD, Broadhurst LM (2016) The economic cost of managing invasive species in Australia. NeoBiota 31:1-18. https://doi.org/10.3897/neobiota.31.6960

Höss M, Kohn M, Pääbo S, et al (1992) Excrement analysis by PCR. Nature 359:199. https://doi.org/10.1038/359199a0

Hulme PE (2016) Trade, transport and trouble: managing invasive species pathways in an era of globalization. J Appl Ecol 46:10-18

International Plant Protection Convention (2014) National Diagnostic Protocol for Plum pox virus (PPV) Plant Health Diagnostic Standards

International Plant Protection Convention (2016) DP 16: GenusLiriomyza . ISPM 27 Diagnostic protocols for regulated pests, p DP 16-33

International Plant Protection Convention (2017) Detection ofLiriomyza sativae in Far North Queensland

Jerde CL, Mahon AR, Chadderton WL, Lodge DM (2011) "Sight-unseen" detection of rare aquatic species using environmental DNA. Conserv Lett 4:150-157. https://doi.org/10.1111/j.1755-263X.2010.00158.x

Johnson MW, Oatman ER, Wyman JA, Van Steenwyk RA (1980) A Technique for Monitoring Liriomyza sativae in Fresh Market Tomatoes. J Econ Entomol 73:552-555. https://doi.org/10.1093/jee/73.4.552 
Kearney SG, Cawardine J, Reside AE, et al (2018) The threats to Australia's imperilled species and implications for a national conservation response. Pacific Conserv Biol. https://doi.org/10.1071/PC18024

Klymus KE, Merkes CM, Allison MJ, et al (2019) Reporting the limits of detection and quantification for environmental DNA assays. Environ DNA 2:271-282. https://doi.org/10.1002/edn3.29

Liebhold AM, Keitt TH, Goel N, Bertelsmeier C (2020) Scale invariance in the spatial-dynamics of biological invasions. NeoBiota 62:269-277. https://doi.org/10.3897/neobiota.62.53213

Lugg WH, Griffiths J, van Rooyen AR, et al (2018) Optimal survey designs for environmental DNA sampling. Methods Ecol Evol 9:1049-1059. https://doi.org/10.1111/2041-210X.12951

Maslo B, Valentin R, Leu K, et al (2017) Chirosurveillance: The use of native bats to detect invasive agricultural pests. PLoS One 12:1-10. https://doi.org/10.1371/journal.pone.0173321

Moore JL, Rout TM, Hauser CE, et al (2010) Protecting islands from pest invasion: optimal allocation of biosecurity resources between quarantine and surveillance. Biol Conserv 143:1068-1078. https://doi.org/10.1016/j.biocon.2010.01.019

Nichols R V., Cromsigt JPGM, Spong G (2015) DNA left on browsed twigs uncovers bite-scale resource use patterns in European ungulates. Oecologia 178:275-284. https://doi.org/10.1007/s00442-014-3196-z

Piaggio AJ, Engeman RM, Hopken MW, et al (2014) Detecting an elusive invasive species: A diagnostic PCR to detect Burmese python in Florida waters and an assessment of persistence of environmental DNA. Mol Ecol Resour 14:374-380. https://doi.org/10.1111/1755-0998.12180

Pilliod DS, Goldberg CS, Arkle RS, Waits LP (2013) Estimating occupancy and abundance of stream amphibians using environmental DNA from filtered water samples. Can J Fish Aquat Sci 70:1123-1130. https://doi.org/10.1139/cjfas-2013-0047

Pimentel D, McNair S, Janecka J, et al (2001) Economic and environmental threats of alien plant, animal, and microbe invasions. Agric Ecosyst Environ 84:1-20. https://doi.org/10.1016/S0167-8809(00)00178-X

Plummer M (2003) JAGS: A program for analysis of Bayesian models using Gibbs sampling. In: Proceedings of the 3rd International Workshop on Distributed Statistical Computing. Vienna, Austria, p 10

Powell DF (1981) The Eradication Campaign Against American Serpentine Leaf Miner Liriomyza trifolii at Efford Experimental Horticulture Station Hampshire, England, UK. Plant Pathol 30:195-204

Rajan (2006) Surveillance and monitoring for plant parasitic nematodes - A challenge. EPPO Bull 36:59-64. https://doi.org/10.1111/j.1365-2338.2006.00942.x

Rejmánek M, Pitcairn MJ (2002) When is eradication of exotic pest plants a realistic goal? IUCN: The World Conservation Union

Rodgers TW, Janečka JE (2013) Applications and techniques for non-invasive faecal genetics research in felid conservation. Eur J Wildl Res 59:1-16. https://doi.org/10.1007/s10344-012-0675-6

Rodgers TW, Mock KE (2015) Drinking water as a source of environmental DNA for the detection of terrestrial wildlife species. Conserv Genet Resour 7:693-696. https://doi.org/10.1007/s12686-015-0478-7

Schneider J, Valentini A, Dejean T, et al (2016) Detection of invasive mosquito vectors using environmental DNA (eDNA) from water samples. PLoS One 11:1-18. https://doi.org/10.1371/journal.pone.0162493

Schnell IB, Thomsen PF, Wilkinson N, et al (2012) Screening mammal biodiversity using DNA from leeches. Curr Biol 22:R262-R263. https://doi.org/10.1016/j.cub.2012.02.058

Schubert G, Stockhausen M, Hoffmann C, et al (2015) Targeted detection of mammalian species using carrion fly-derived DNA. Mol Ecol Resour 15:285-294. https://doi.org/10.1111/1755-0998.12306 
Shiao SF (2004) Morphological diagnosis of six Liriomyza species (Diptera: Agromyzidae) of quarantine importance in Taiwan. Appl Entomol Zool 39:27-39. https://doi.org/10.1303/aez.2004.27

Sigsgaard EE, Carl H, Møller PR, Thomsen PF (2015) Monitoring the near-extinct European weather loach in Denmark based on environmental DNA from water samples. Biol Conserv 183:46-52. https://doi.org/10.1016/j.biocon.2014.11.023

Smart AS, Tingley R, Weeks AR, et al (2015) Environmental DNA sampling is more sensitive than a traditional survey technique for detecting an aquatic invader. Ecol Appl 25:1944-1952. https://doi.org/10.1890/141751.1

Sooda A, Gunawardana D, Li D, Kumarasinghe L (2017) Multiplex real-time PCR assay for the detection of three invasive leafminer species: Liriomyza huidobrensis, L. sativae and L. trifolii (Diptera: Agromyzidae). Austral Entomol 56:153-159. https://doi.org/10.1111/aen.12237

Spencer KA (1973) Agromyzidae (Diptera) of Economic Importance. 9:418. https://doi.org/10.1007/978-94017-0683-4

Spencer KA (1990) Host specialization in the world Agromyzidae (Diptera). Host Spec world Agromyzidae. https://doi.org/10.2307/4110790

Thomsen PF, Kielgast J, Iversen LL, et al (2012) Monitoring endangered freshwater biodiversity using environmental DNA. Mol Ecol 21:2565-2573. https://doi.org/10.1111/j.1365-294X.2011.05418.x

Thomsen PF, Sigsgaard EE (2019) Environmental DNA metabarcoding of wild flowers reveals diverse communities of terrestrial arthropods. Ecol Evol 9:1665-1679. https://doi.org/10.1002/ece3.4809

Timmins SM, Braithwaite H (2003) Early detection of invasive weeds on islands. IUCN: The World Conservation Union

Valentin RE, Fonseca DM, Nielsen AL, et al (2018) Early detection of invasive exotic insect infestations using eDNA from crop surfaces. Front Ecol Environ 16:265-270. https://doi.org/10.1002/fee.1811

Waits LP, Paetkau D (2005) Noninvasive Genetic Sampling Tools for Wildlife Biologists: a Review of Applications and Recommendations for Accurate Data Collection. J Wildl Manage 69:1419-1433. https://doi.org/10.2193/0022-541x(2005)69[1419:ngstfw]2.0.co;2

Walsh PS, Metzger DA, Higuchi R (1991) Chelex@ 100 as a medium for simple extraction of DNA for PCR-based typing from forensic material. Biotechniques 10:506-513. https://doi.org/10.2144/000114018

Williams CL, Johnston JJ, Blejwas K, Jaeger MM (2003) A coyote in sheep's clothing: Predator identification from saliva. Wildl Soc Bull 31:926-932

Zehnder GW, Trumble JT (1984) Spatial and Deil Activity ofLiriomyza species (Diptera: Agromyzidae) in fresh market tomatoes. Environ Entomolgy 13:1411-1416. https://doi.org/10.1093/ee/13.5.1411 